\title{
meeting reviews
}

\section{"The Future of Laboratory Research and Facilities for Cloud Physics and Cloud Chemistry": ${ }^{1}$}

\author{
Report on a Technical Workshop Held in Boulder, Colorado, \\ 20-22 March 1985 \\ Roland List ${ }^{2}$, John Hallett ${ }^{3}$, Jack Warner ${ }^{4}$, Roger Reinking ${ }^{5}$ \\ Conference Chairman and Steering Committee Members
}

\begin{abstract}
A technical workshop was held to review areas and goals of laboratory research in cloud physics and cloud chemistry, define the basic and practical utility of such research in terms of past accomplishments and future potential, assess the status and needs for existing and new facilities, and recommend future direction for laboratory research and corresponding facilities development in the disciplines of atmospheric science affected by cloud processes. The findings are reported in this workshop summary.

The findings show that laboratory research in cloud physics and cloud chemistry has been a very productive and necessary complement to field and modeling studies, that a high potential for fundamental and significant benefits to a wide range of the atmospheric sciences remains, and that these benefits can only be realized through upgrades in existing facilities and, particularly, through development of new facilities with specific and important new capabilities. The latter might best be accomplished within the concept of a national capability.
\end{abstract}

\section{Introduction}

A technical workshop titled "The Future of Laboratory Research and Facilities for Cloud Physics and Chemistry," was held in Boulder from 20-22 March 1985. It was cosponsored by the Environmental Research Laboratories of the National Oceanic and Atmospheric Administration (NOAA) and the National Center for Atmospheric Research (NCAR).

The workshop stemmed from a recognition of the necessity of laboratory research as basic support for field and mod-

\footnotetext{
${ }^{1}$ The report has been circulated among all participants of the workshop and many of their comments have been accommodated in the final version.

${ }^{2}$ Dept. of Physics, University of Toronto, Toronto, Canada M5S-1A7.

${ }^{3}$ Desert Research Institute, University of Nevada, Reno, NV 89506.

${ }^{4}$ National Center for Atmospheric Research, Boulder, CO 80307.

${ }^{5}$ Environmental Research Laboratories, National Oceanic and Atmospheric Administration, Boulder, CO 80303.
}

eling investigations of clouds, and from the belief that such laboratory research over the past two decades has declined to such an extent that scientific progress toward understanding many processes occurring in the atmosphere is being impeded.

The workshop had six express purposes: 1) review the scientific problem areas in cloud physics and cloud chemistry that require laboratory research;2) point out future directions of laboratory research with its interrelations to field observations and numerical modeling; 3 ) determine the utilization, limitations and potential of existing laboratory facilities; 4) discuss the advantages for new facility designs and small-and large-scale multi-purpose laboratory facilities; 5) underline the need of facilities for operational problems like icing and aircraft instrument calibrations; and 6) produce a definitive set of recommendations for future laboratory research in Cloud Physics and Cloud Chemistry.

The workshop was attended by 85 scientists and engineers from civilian and defense government agencies, universities, research institutions, and the private sector. It was chaired by Roland List from the University of Toronto; assisted by a steering committee of Norihiko Fukuta, University of Utah; John Hallett, Desert Research Institute; Kenneth Beard, Illinois State Water Survey; Jack Warner and Byron Phillips, NCAR; and Roger Reinking, ERL/NOAA. The present report summarizes the key aspects and results of the workshop.

\section{The goals of cloud-physics and cloud- chemistry research with particular attention to laboratory investigations}

Cloud-physics and -chemistry laboratory research is carried out, in part, to clarify the processes participating in the formation and evolution of clouds, but the discipline is carried well beyond this by other basic scientific needs and many focused applications.

Among the basic goals and exemplary applications of cloud physics and cloud chemistry are these:

1) to understand, analytically describe, and predict the microphysical formation, development, and evolution 
TABLE 1. Current laboratory facilities for studying particle interactions.

\begin{tabular}{|c|c|c|c|c|c|c|c|c|}
\hline & Vapor & Aerosol & $\begin{array}{c}\text { Cloud } \\
\text { droplet* }\end{array}$ & $\begin{array}{l}\text { Rain } \\
\text { drop** }\end{array}$ & $\begin{array}{l}\text { Snow } \\
\text { crystal } \\
(\mu \mathrm{m})^{*}\end{array}$ & $\begin{array}{c}\text { Snow } \\
\text { crystal } \\
(\mathrm{mm})^{* *}\end{array}$ & Graupel & Hail \\
\hline Vapor & $\mathrm{S}$ & & & & & & & \\
\hline Aerosol & $\mathrm{S}, \mathrm{C}, \mathrm{E}, \mathrm{H}$ & C & & & & & & \\
\hline Cloud droplet* & E,D & $\mathrm{E}, \mathrm{D}, \mathrm{F}$ & $\mathrm{C}, \mathrm{E}$ & & & & & \\
\hline Rain drop** & $\mathrm{T}$ & $\mathrm{F}, \mathrm{T}$ & $\mathrm{F}, \mathrm{T}$ & $\mathrm{F}, \mathrm{T}$ & & & & \\
\hline $\begin{array}{l}\text { Snow crystal } \\
(\mu \mathrm{m})^{*}\end{array}$ & C,D,E,T & E,D & $\mathrm{D}, \mathrm{T}$ & $\mathbf{F}$ & $\mathrm{C}$ & & & \\
\hline $\begin{array}{l}\text { Snow crystal } \\
(\mathrm{mm})^{* *}\end{array}$ & $\mathrm{D}, \mathrm{T}$ & E,D,F,T & $\mathrm{D}, \mathrm{F}, \mathrm{T}$ & $\mathrm{U}$ & $\mathrm{U}$ & $\mathrm{U}$ & & \\
\hline Graupel & $\mathrm{T}$ & $\mathrm{C}, \mathrm{T}$ & $\mathrm{C}, \mathrm{D}, \mathrm{T}$ & $\mathrm{U}$ & $\mathrm{T}$ & $\mathrm{U}$ & $\mathrm{U}$ & \\
\hline Hail & $\mathrm{T}$ & $\mathrm{T}$ & $\mathrm{T}$ & $\mathrm{U}$ & $\mathrm{T}$ & $\mathbf{U}$ & $\mathrm{U}$ & $\mathbf{U}$ \\
\hline
\end{tabular}

C-simple laboratory chamber; S-smog chamber; H-haze chamber; E-expansion chamber; D-dynamic-diffusion chamber; F-fall column; T-wind tunnel (suspension); U-unavailable. *-Diameter $<200 \mu \mathrm{m}$; **-Diameter $>200 \mu \mathrm{m}$.

of cloud and precipitation particles in interactive relation with the dynamics of clouds;

2) to determine the transmission, absorption, refraction and/or reflection or backscatter of visible, infrared, and microwave radiation by clouds of varied hydrometeors and aerosols;

3) to assess the role of clouds in the radiation, heat, and water balance of the earth and, consequently, determine their effect on global and regional weather and climate;

4) to describe the role of clouds and precipitation in processing pollutants and natural aerosol and gaseous chemicals in the atmosphere and in cleansing the atmosphere, and describe the effects of these atmospheric chemicals on precipitation processes;

5) to improve quantitative forecasting of precipitation and associated severe-weather phenomena (e.g., heavy and flood-inducing rains, hail, freezing rain, snow storms and blizzards, downbursts, tornadoes, and thunderstorm and hurricane winds) through better understanding of the role of microscale processes;

6) to determine the realities of potentials for purposefully and beneficially influencing the microphysical and dynamical development of precipitation;

7) to assess the linkages between cloud and precipitation processes and contemporary problems like acid-rain deposition and nuclear winter; and

8) to quantify the physics of the effects of clouds on objects (e.g., icing of aircraft, powerlines, ships, and drill rigs; and frictional abrasion of aircraft or space vehicles during high-speed impact with different types of aerosols or precipitation particles).

\section{Basic laboratory experiments}

Laboratory studies in cloud physics and cloud chemistry are highly suited for investigation of the basic microphysical processes of cloud-droplet and ice-crystal generation (nucleation), their growth to precipitation particles (drizzle, raindrops, snowflakes, graupel, and hail) and their interaction with aerosols and gases.
For the characterization of laboratory experiments, the following terminology will be used hereafter: processes involving one family of particles (e.g., a cloud of droplets; or snow crystals only) will be called single interactions. Processes involving one type of precipitation particle and a cloud (droplets and drops or ice particles of a particular kind) will be called double interactions. If aerosol particles, or gases other than air are involved, the word plus will be added to indicate the added chemical influences to the process. Processes involving two kinds of precipitation particles and a cloud will be called triple interactions. Thus, triple-plus interactions would indicate the interplay between a cloud and two types of precipitation particles with differing aerodynamics in the presence, and with the involvement of aerosols and/or atmospheric trace gases.

Facilities presently in use for single and double interactions (sometimes with chemical components) are: expansion, mixing, diffusion and flow-diffusion chambers, drop columns, and icing wind tunnels.

In addition to the above, problems of buoyancy, mixing, and convection have been and still are studied in the laboratory. For example, small-scale convective and mixing motions could be important for droplet-growth and ice-crystalaggregation studies, and scaled laboratory experiments on cloud mixing may yield results similar in importance to those in modeling of fluid mixing.

The particular interactions that have been studied up to now, and which would be studied further if suitable laboratory facilities were available, are listed in Table 1.

\section{Advances due to laboratory research}

The following are examples of relatively recent laboratory accomplishments that have been crucial to our understanding and ability to predict the effects of particles and how they evolve in the atmosphere: 1) separation of ice-nucleation mechanisms under different environmental conditions and nucleus characteristics; 2 ) the role of bacteria in ice nucleation and the pertinence of this to frost protection; 3 ) the role of specific oxidants in $\mathrm{SO}_{2}-\mathrm{SO}_{3}$ conversion; 4) ability to 
TABLE 2. Summary of major existing laboratory facilities in North America for cloud physics and cloud chemistry studies.*

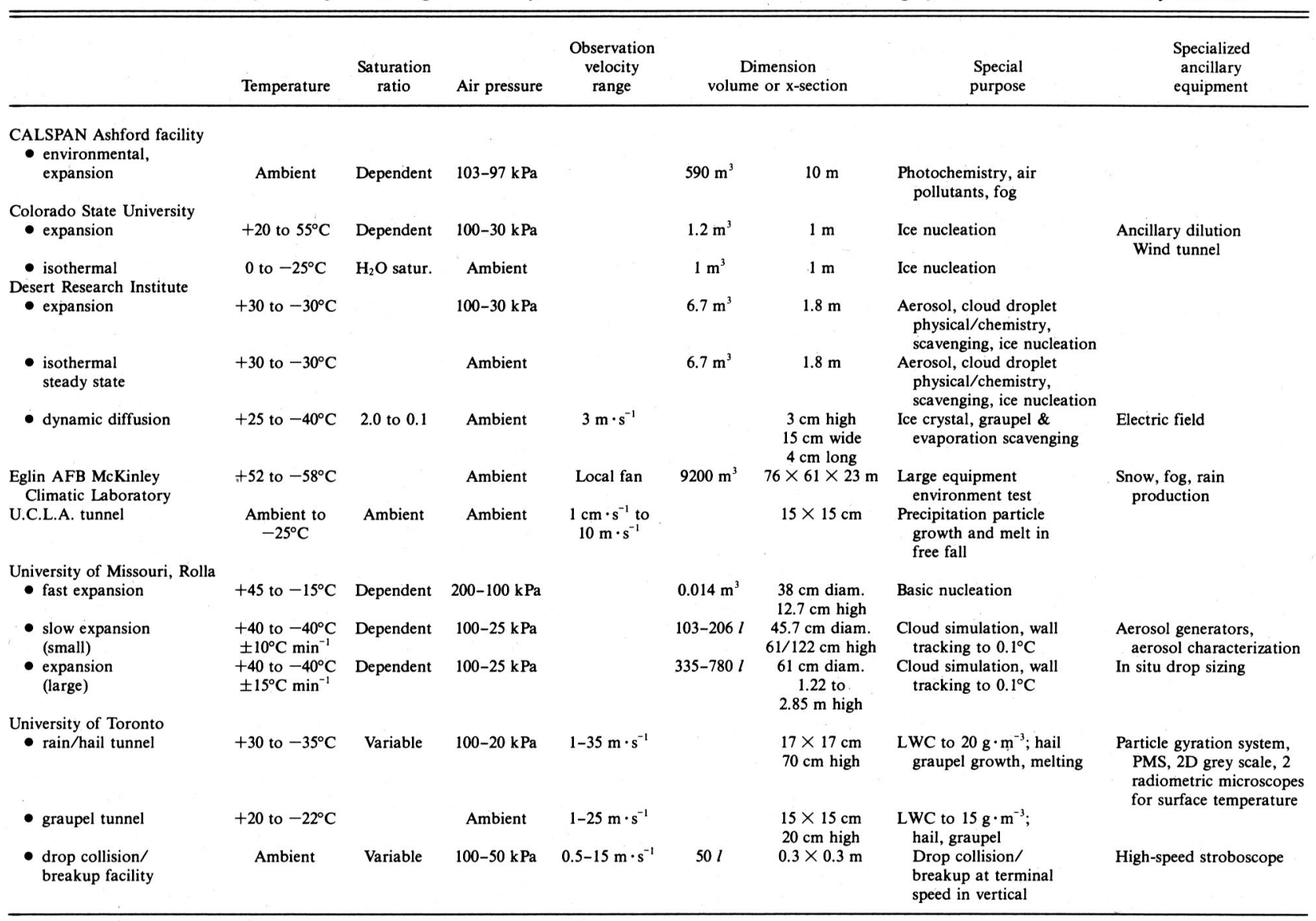

* In addition to these facilities, a number of aircraft icing tunnels also exist in the United States and Canada; see, e.g., Olsen, 1981.

characterize cloud condensation nuclei according to supersaturation; 5) secondary ice-crystal production during the growth of graupel, related to temperature and the clouddroplet-size spectrum; 6) oscillation of falling raindrops and its importance in interpretation of radar reflectivity; 7) role of collisions in breakup of raindrops and their importance in producing an equilibrium size distribution in warm rain; 8) necessity for triple interactions (graupel, supercooled droplets, ice crystals) to produce graupel electrification; 9) shedding of millimeter-size drops by growing and melting hailstones; 10) influence of environmental parameters on the growth rate, shape, and fall velocity of snow crystals, and the onset of skeletal growth at critical fall velocity; 11) importance of mixing in shaping a cloud-droplet spectrum and initiating precipitation.

Reference to these and other studies can be found in the standard texts and in review papers, e.g., P. V. Hobbs, 1974; H. R. Pruppacher and J. D. Klett, 1978; W. Cotton, 1979; and J. Hallett, 1983.

The discoveries listed above are typical of laboratory results; they could not have been achieved in any other way. Many of them have already been incorporated into models, utilized to provide guidance for verification of hypotheses through in situ measurements in natural clouds, and related to results from the field in order to assess their overall significance to cloud physics as a whole.

\section{Existing facilities}

Existing facilities provide an excellent basic resource for continuing experimentation ranging from single to double-plus interactions. An inventory of the major facilities, each with equipment investments exceeding $\$ 100,000$, is given in Table 2 . They serve purposes of fundamental as well as applied research. They are basically sound and proven for their specific, intended uses; many of them, however, lack sophisticated monitoring and measuring systems. Figures 1-11 give some visual impressions of presently available facilities.

\section{The need for continuation of laboratory experiments on single, double, and related "plus" interactions}

A review of the status of cloud physics reveals that our knowledge of the most basic hydrometeor generation and growth processes for cloud particles (e.g., nucleation, collision/coalescence growth, breakup, accretion and agglomeration, ice-particle multiplication, shedding, etc.) needs to be expanded, and past experimental results need to be upgraded 

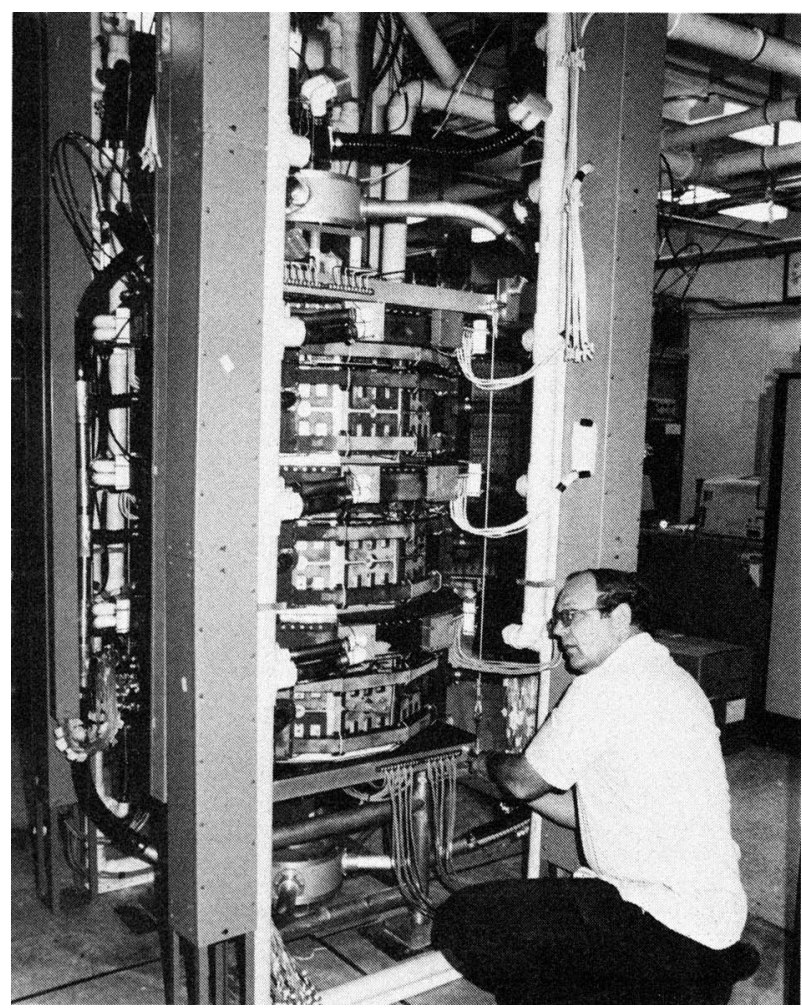

FIG. 1. Large, cooled-wall, slow-expansion cloud-simulation chamber with a diameter of $0.61 \mathrm{~m}$, and a variable height of 0.81 to $2.84 \mathrm{~m}$; at the University of Missouri-Rolla (one of a series of chambers); Dan White in photo. (Photo courtesy John C. Carstens.)

with state-of-the-art equipment. Many new experiments should also include electrical effects because there is still a great lack in understanding of charge separation in thunderstorms.

Chemical studies on the interplay between gaseous and particle pollution and microphysical processes in a cloudy atmosphere have barely begun; substantial work on these topics should be encouraged with existing facilities. Indeed, some further study of particular physical single or double interactions and associated chemical plus interactions is warranted within the purview of essentially every basic or applied goal cited in Section 2.

\section{Triple interactions and other high-priority experiments}

\section{a. Triple and triple-plus interaction experiments}

Existing facilities (Section 5) allow, at most, the study of formation and growth of one type and size of precipitation particle in a cloud. In real clouds, however, drops and ice particles, both with sizes $>200 \mu \mathrm{m}$ often occur together, and the sizes are distributed over varied spectra. The challenge of experimentally simulating such conditions is to achieve and maintain the terminal fallspeeds for both types of precipitation particles relative to the surrounding air, for sufficient

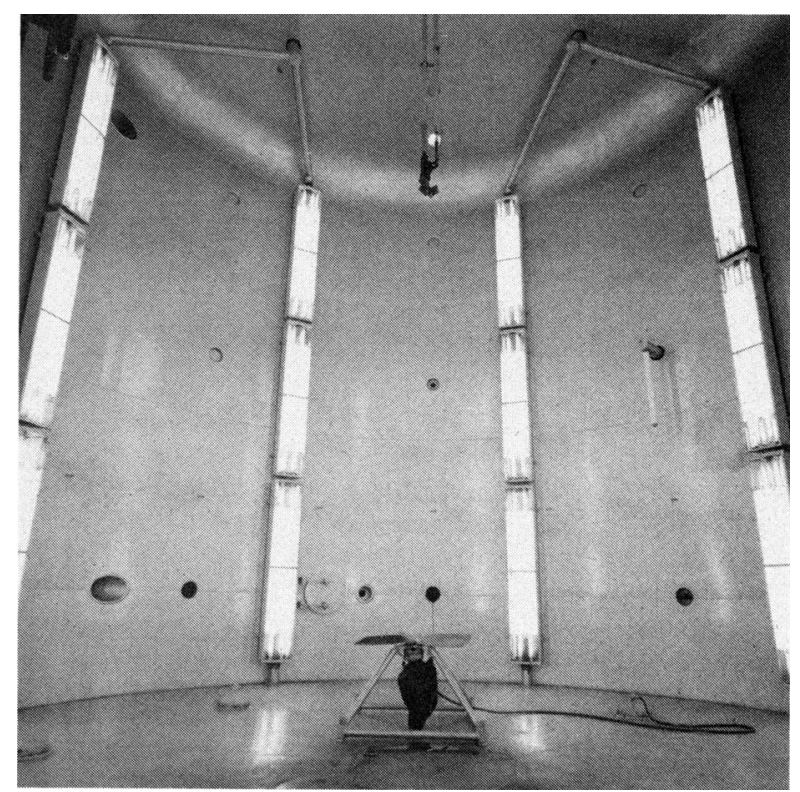

FIG. 2. Inside view of the $600 \mathrm{~m}^{3}$ photochemical aerosol chamber at Arvin Calspan, Advanced Technology Center, Buffalo, New York. (Photo courtesy Roland Pilie.)

time to hold the particles and observe the processes of interest within a confined volume.

Fundamentally important triple and triple-plus interaction experiments include

1) The formation and evolution of precipitation through interactions of two types of precipitation particles (any two of the following: drops, large ice crystals $[>200 \mu \mathrm{m}]$, snowflakes, graupel and hail) with clouds of droplets and/or small ice crystals $(<200$ $\mu \mathrm{m})$. Added broad aspects include production, separation and effects of electric charges and fields, and scavenging and washout of aerosols and trace gases.

2) Snow formation by ice-crystal aggregation, with and without effects of electrostatic charging.

3) Secondary ice formation for the delineation of cloud conditions where ice multiplication is predominant over ice nucleation-an influential phenomenon for both precipitation prediction and artificial rain enhancement.

4) Corona propagation through hydrometeor populations, for the better understanding of electrical behavior of thunderstorms.

5) The fast spectral evolution of cloud droplets in the presence of mixing, a phenomenon that might be decisive in the initiation of precipitation by the warm-rain mechanism.

Present facilities to study these and related effects are inadequate and new facilities are required.

\section{b. Other substantive problems with high-priority applications}

6) Measurements of optical and microwave backscattering cross-sections, attenuation and depolarization by 
hydrometeors in varied single-phase and mixed-phase clouds, for proper interpretation of signals from remote sensing of clouds. This is important to the utilization of cloud remote sensors in research and applications; in particular, it is important in the context of such efforts as the proposed National STORM Program, to understanding and interpreting the data streams from new weather remote sensors coming into operational use nationwide.

7) Measurements of visible and infrared radiation reflection, transmission, and absorption by varied singleand mixed-phase clouds (e.g., ice crystals or transient supercooled droplets such as those occurring in cirrus clouds), to better assess the role of clouds in climate, and to determine cloud effects on laser and infrared instrumentation with defense and civilian applications.

Both these investigations conceivably might be done in existing facilities, subject to major modifications.

Of further importance in immediate applications are the following:

8) Calibration of instruments for experimental and operational field measurements of a physical and chemical nature from aircraft.
9) Experiments to better assess the specific characteristics of clouds that cause severe icing on aircraft, drill rigs, ships, and electrical transmission lines.

10) Erosion and electric charging of specialized surfaces under icing conditions or by precipitation particles or aerosols, as applied to aircraft, rockets, and space vehicles.

\section{Facility for triple-plus interactions}

Triple and triple-plus interactions need to be understood, and facilities with new capabilities are required to carry out the necessary studies; these points are certain. Many of the problems and costs involved in tackling triple and triple-plus interactions with new equipment may well demand a consolidation of resources into a single, national facility, or a set of national facilities, that would be suitable for a wide variety of experimental work that cannot be undertaken with existing facilities. Through cost-sharing of such a national capability, each of several agencies and institutions participating in the program would have access to facilities that would be impossible to obtain within their independent budgets and, indeed,

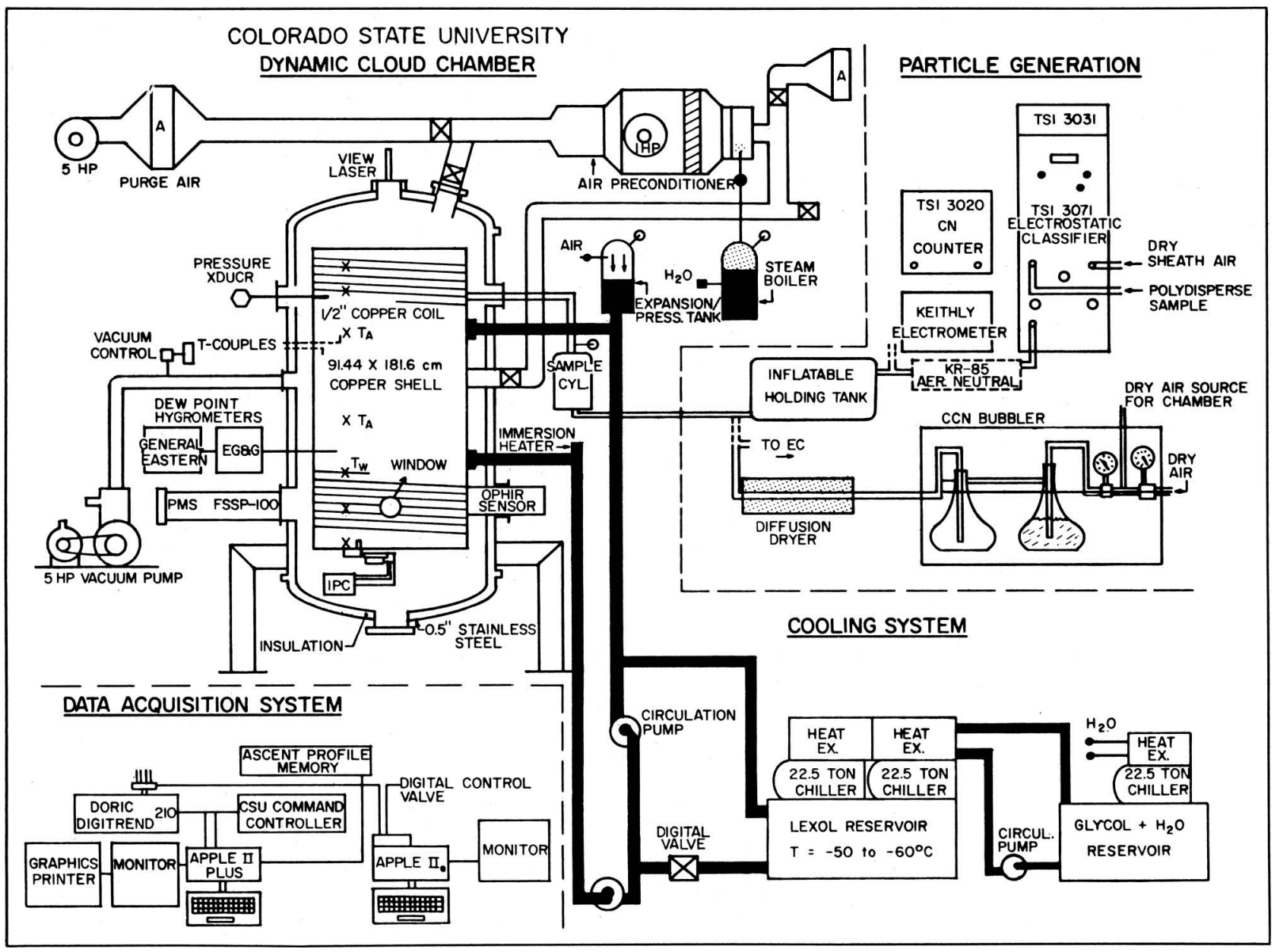

FIG. 3. Schematic diagram of the dynamic cloud chamber of the Colorado State University. (Diagram courtesy Paul J. DeMott.) 


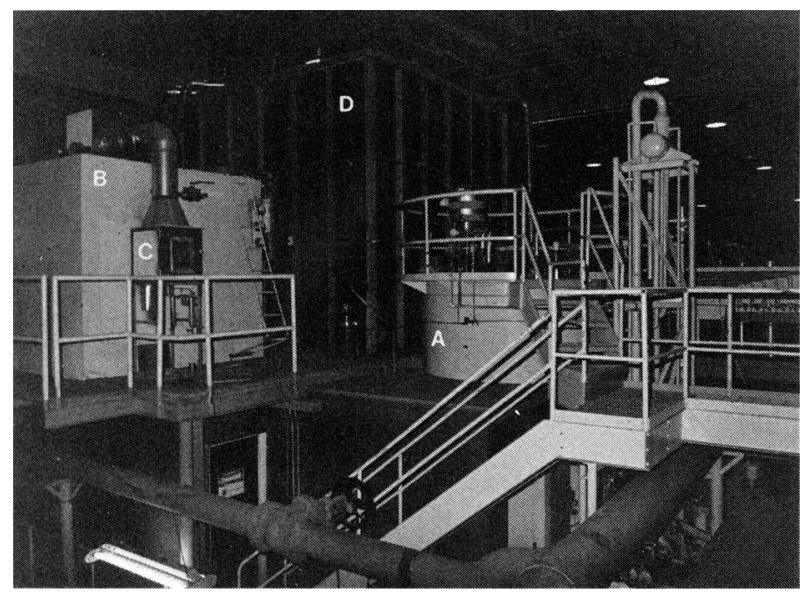

FIG. 4. Cloud-chamber facility at the Desert Research Institute, Reno, Nevada. A: The $617 \mathrm{~m}^{3}$ expansion cloud chamber and associated wall-cooling system on right side. B: A $10 \mathrm{~m}^{3}$ aerosol storage/aging chamber. $C$ : Aerosol generation box with venting capabilities. D: A $53 \mathrm{~m}^{3}$ aerosol storage/aging chamber. (Photo courtesy Dennis Lamb.)

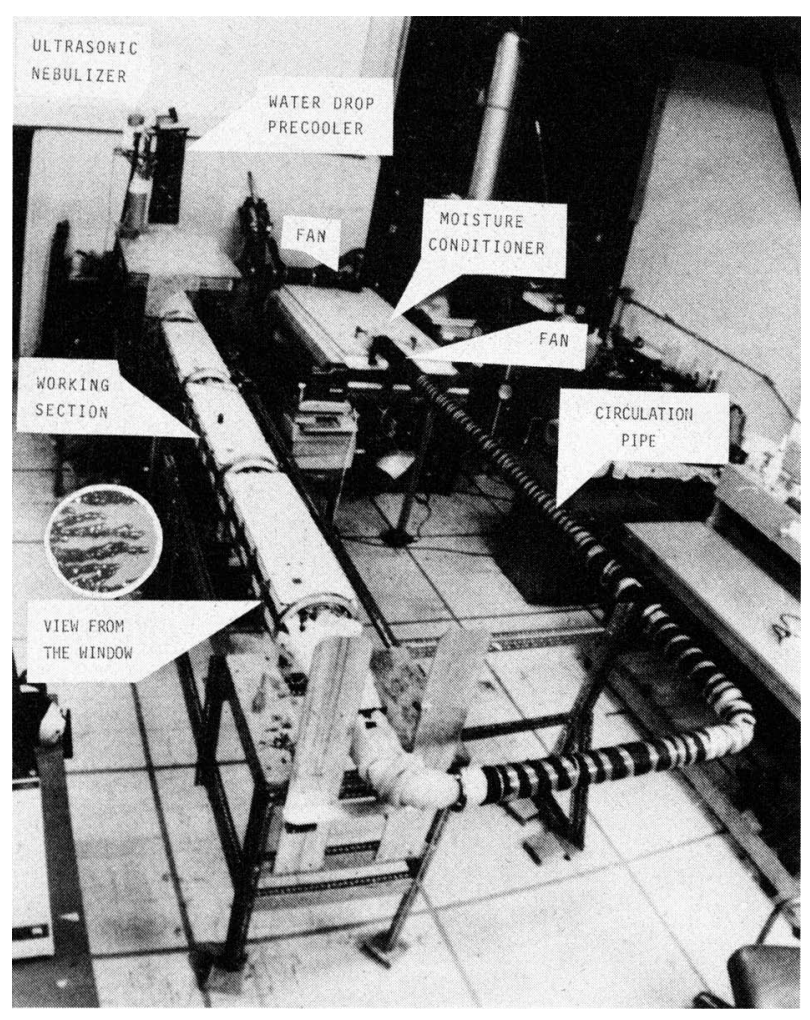

FIG. 5. Thermal, continuous-flow diffusion chamber for studies of cloud-physics processes under controlled temperature, supersaturation, wind speed, and cloud liquid-water content; temperature range $+30^{\circ}$ to $-6^{\circ} \mathrm{C}$; at the Desert Research Institute, Reno, Nevada. (Photo courtesy John Hallett.)

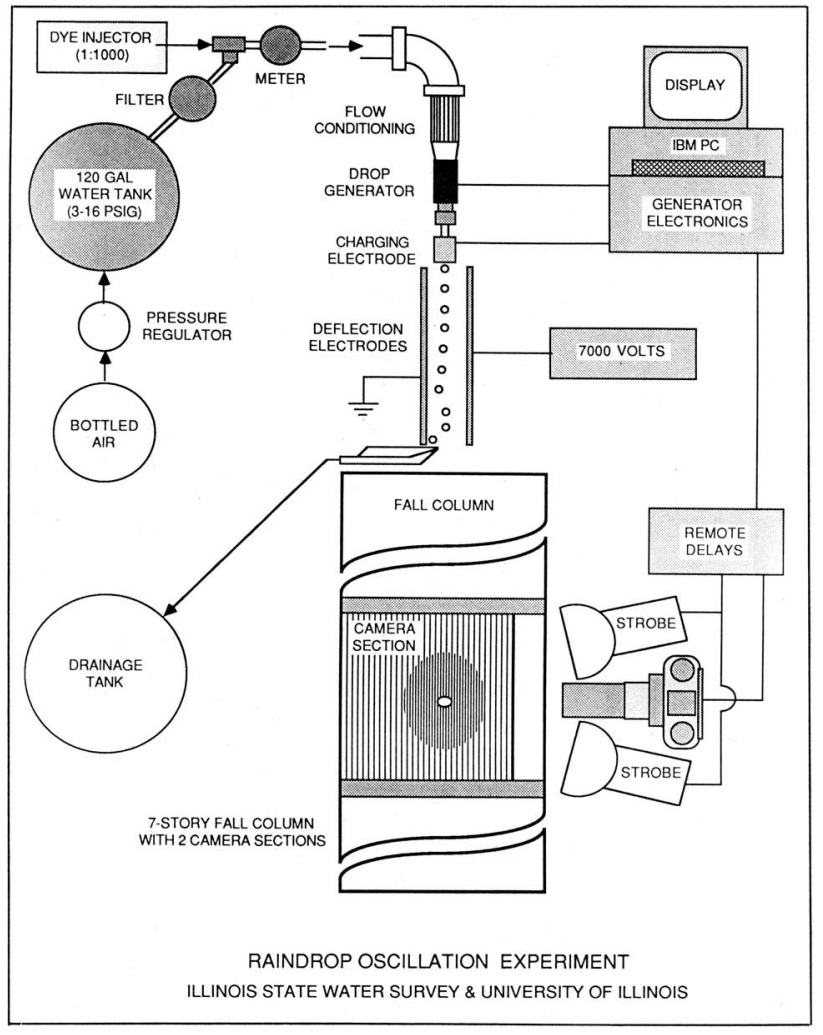

FIG. 6. Configuration for a raindrop-oscillation experiment; at the Illinois State Water Survey and the University of Illinois, Urbana, Illinois. (Diagram courtesy Kenneth V. Beard.)

combining of resources in this manner would result in collective capabilities that far exceed the sum of the individual components. At this time, it is too early to specify the exact nature of this kind of capability, but a few general statements can be made in support of this approach.

Parallels for this kind of national facility, or facilities, do exist in high-energy physics and in astronomy. High cost has been the main factor forcing collaboration and consolidation of resources to address key scientific problems. Important studies, as well as the training of students, via operation of smaller, specialized facilities at individual institutions are by no means excluded. In this perspective, the community of cloud physicists and chemists might do well to seriously examine the national facility approach and objectively assess its feasibility.

The parallels of high-energy physics with cloud physics and chemistry extend to the science. In both fields, particles with different sizes and energies need to be produced, stored, and retrieved; accelerated and collided with each other; and observed during interactions. Just as particles of uniform (or measurably distributed) size and mass are required in highenergy physics, the required cloud research to be done in a triple-interaction facility necessitates new technology for producing hydrometeors of controlled uniform or distributed size and shape. Water, ice, or mixed clouds in a triple-interaction facility would be produced and stored in large con- 


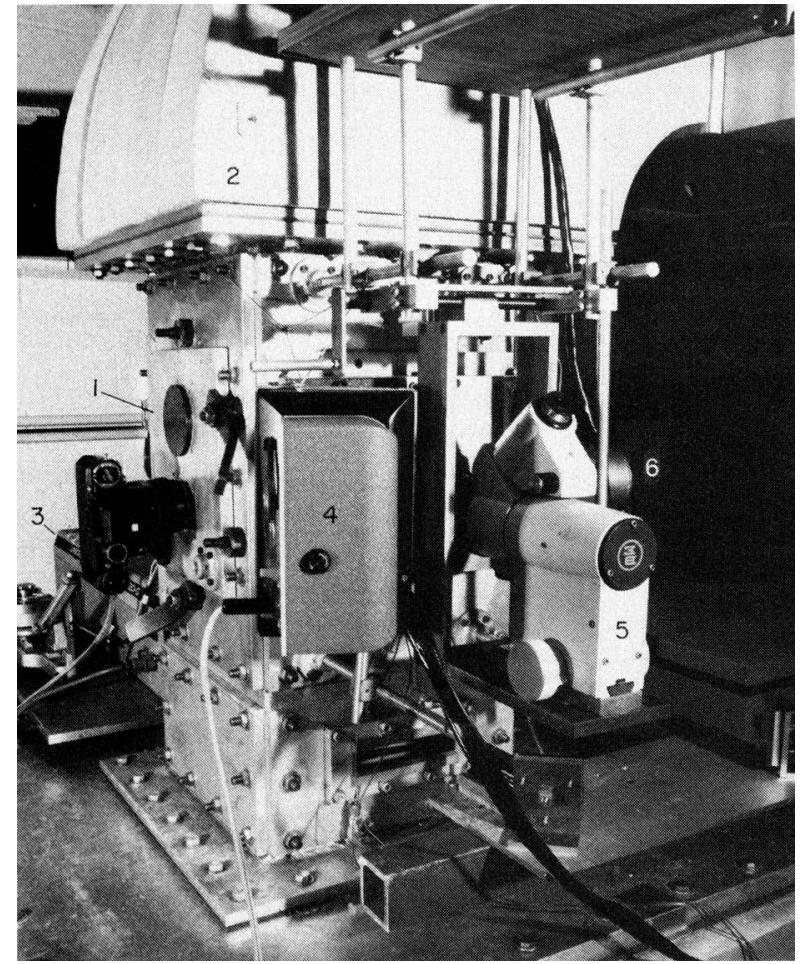

FIG. 7. The measuring section of the pressure-controlled COLD RAIN AND HAIL SIMULATOR; speed range $1-35 \mathrm{~m} \cdot \mathrm{s}^{-1}$, temperature $+30^{\circ}$ to $-35^{\circ} \mathrm{C}$, pressure $150 \mathrm{kPa}$ to $20 \mathrm{kPa}$. LWC up to 10 $\mathrm{g} \cdot \mathrm{m}^{-3}$ and more, with adjustable drop size distributions. 1) measuring section with access door, 2) return duct to fan, 3) PMS 2-DC probe with grey scale, 4) stroboscope, 5) inf rared microscope for surface-temperature measurements of test particles, 6) gyrator, forcing suspended hailstones to carry out most general motions in air stream. System includes video and other cameras. (Photo courtesy Roland List.)

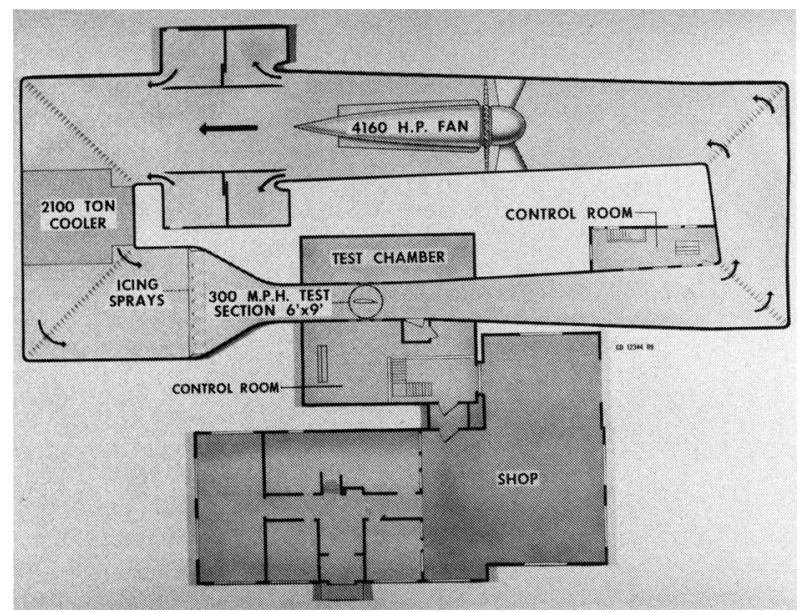

FIG. 8. Schematic diagram of the icing-research tunnel at the Lewis Research Center, Cleveland, Ohio (Diagram courtesy Andrew L. Reehorst.)

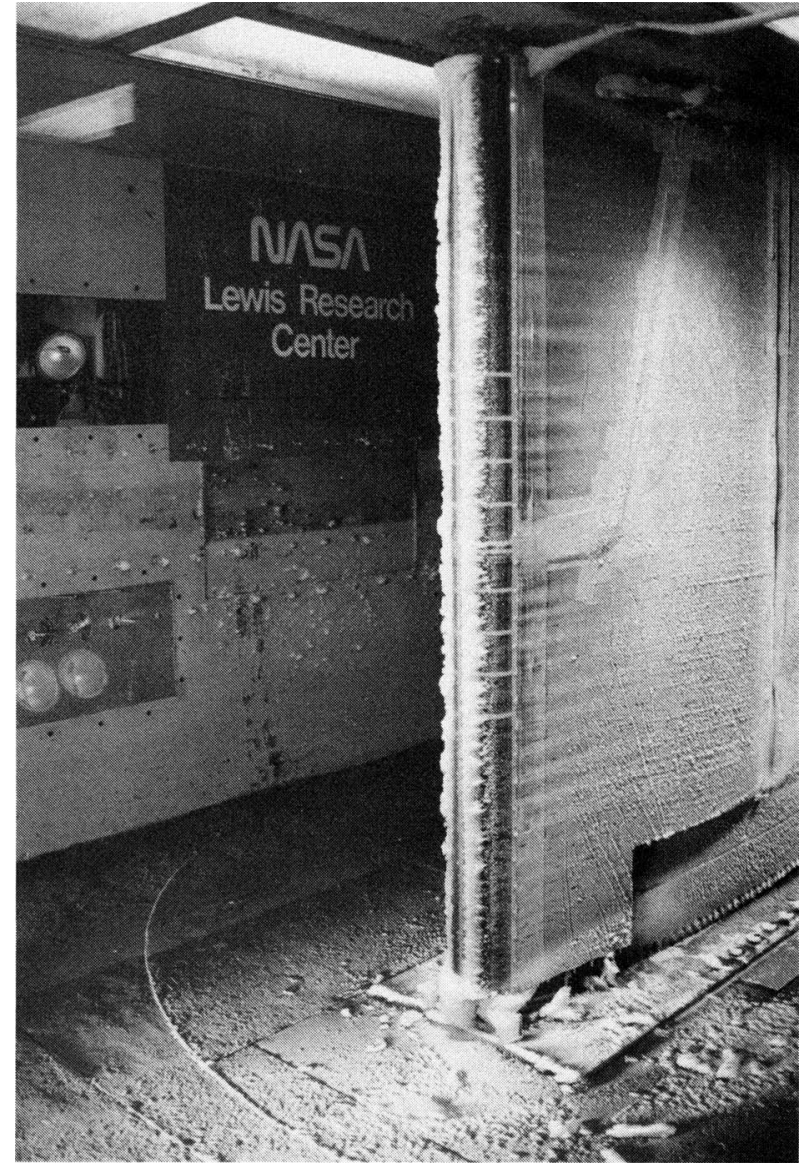

FIG. 9. Icing test of airfoil in $2.7 \times 1.8 \mathrm{~m}$ cross section of icing research tunnel at Lewis Research Center, Cleveland, Ohio. (Photo courtesy Andrew L. Reehorst.)

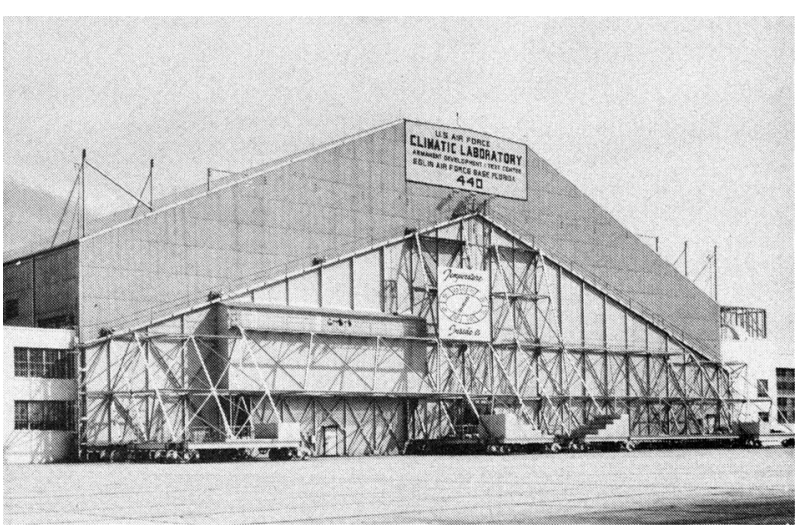

FIG. 10. Climatic Laboratory at the Eglin Air Force Base in Florida. Width $76 \mathrm{~m}$, depth $61 \mathrm{~m}$, height $23 \mathrm{~m}$ at center; temperature range $+74^{\circ} \mathrm{C}$ to $-54^{\circ} \mathrm{C}$. (Photo courtesy C. Wayne Drake.) 


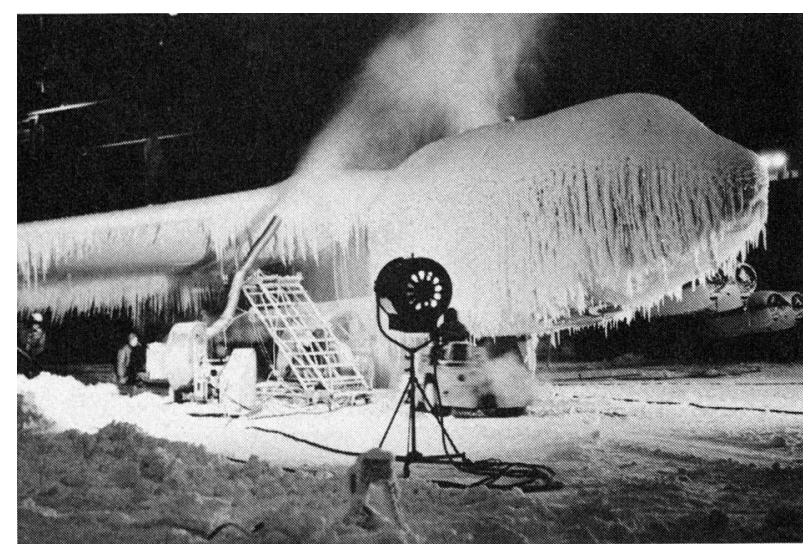

FIG. 11. C-5A aircraft in climatic laboratory of the Eglin Air Force Base in Florida, see Fig. 10. (Photo courtesy C. Wayne Drake.)

trolling "reservoirs" (e.g., 50-100 m diameter) for interaction experiments with precipitation particles. Secondary precipitation particles would be prepared and stored in an auxiliary vertical wind tunnel until injection - with the cloud from the storage tank-into the main interaction chamber in which the growth of the primary precipitation particles would be observed.

Past laboratory experiments have shown that the continuous growth of graupel, drops, or hailstones is best studied in a vertical wind tunnel. It is therefore assumed that the main interaction chamber would be part of a main vertical wind tunnel. The desirable temperature range would be $+20^{\circ}$ to $-45^{\circ} \mathrm{C}$.

A horizontal mixed-phase-hydrometeor wind tunnel could be added, because a storage facility for cloud and measuring equipment for ice growth would already be available. This tunnel would be valuable for much-needed calibration, improvement, and development of cloud-sampling instruments carried by aircraft. By providing better hydrometeor-measurement capabilities over the ranges of aircraft speeds, the instrumentation activity together with the mixed-phase (ice plus water) cloud capability would also substantially augment the limited versatility of present icing tunnels. The horizontal tunnel would also be very useful for certain electricalcharging experiments.

A futuristic view by N. Fukuta of an advanced cloud physics facility is shown in Figure 12.

\section{Recommendations}

\section{a. Existing facilities}

Recognizing that laboratory research-in concert with theoretical and numerical modeling studies and field observations-is essential for the effective exploration of cloud physics and cloud chemistry and for the nationally important training of graduate meteorology, chemistry, and physics students in advanced experimental work in the atmospheric sciences, the workshop recommendations for existing facilities are
1) that the present laboratory facilities be modernized where necessary and upgraded by state-of-the-art and computer-on-line measuring equipment in order to keep abreast with the technological advances and thus improve scientific productivity;

2) that the infrastructure of the facility operations be substantially upgraded for improved efficiency, and that the available equipment be used more fully and shared among the experimental cloud-physics and atmosphericchemistry communities;

3) that increased use be made of available facilities to study fundamental chemical processes involved in cloud and aerosol evolution, and aspects of pollution washout by precipitation, as applied for example, to acid rain, nuclear winter, and effects of cloud chemistry on precipitation; and

4) that some existing facilities be modified for the study of: a) scattering, attenuation, polarization and depolarization of radiation and other forms of electromagnetic waves by ice crystals and other precipitation particles, and b) lightning propagation in falling precipitation.

\section{b. New facilities}

To further understand and predict the behavior of clouds, their evolution and precipitation, their scientific importance, and their practical significance in the wide range of applications, the Workshop recommendations are for a substantial expansion of the scope of laboratory cloud physics and chemistry research beyond the reach of the presently available facilities into the realm of triple-plus interactions. Such interactions occur between clouds of droplets and/or ice crystals with two types of precipitation particles (e.g., large ice crystals, snowflakes, graupel, raindrops, hailstones), and in the presence of electrical fields and charges as well as aero-

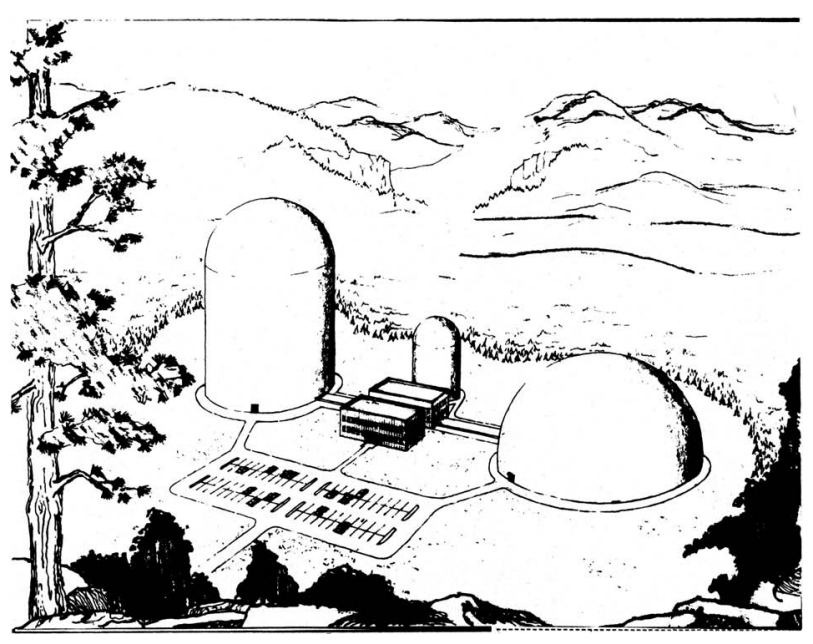

FIG. 12. Conception of a national cloud and precipitation research facility, with two soft-shelled domes (1: diameter $80 \mathrm{~m}$, height $120 \mathrm{~m}, 2$ : diameter $120 \mathrm{~m}$, height $60 \mathrm{~m}$ ), connected by a $300 \mathrm{~m}$ long fog corridor with a mixed-phase icing tunnel. The smaller chamber (diameter $30 \mathrm{~m}$, height $50 \mathrm{~m}$ ) behind the office and support facility buildings is hard-shelled for adiabatic expansion and compression; it is connected to the fog corridor. A vertical wind tunnel may be placed in any of the shell structures. (Courtesy N. Fukuta) 
sols and trace gases. A step-by-step approach in planning families of individual triple-plus interaction experiments would ensure that a proposal for a national capability of one or more facilities would effectively and efficiently fulfill individual and collective requirements. Thus, in particular the workshop recommends

1) that a long-term planning mechanism be established now for designing, developing, and establishing a tripleplus interaction facility or facilities in order to propel laboratory cloud physics and cloud chemistry into a new, highly sophisticated era meeting new challenges and offering scientific progress; this capability would serve the national and international cloud-physics and cloud-chemistry communities;

2) that subsets or families of definitive triple-plus interaction experiments be developed, together with detailed requirements for an appropriate facility for each experiment family, to be combined in the design of a general facility or facilities;

3) that a mixed-phase hydrometeor wind tunnel be considered together with such facility requirements, for such work as instrument calibration, icing studies, and related electrical charging; and

4) that, in the planning and design phase, one or more existing double interaction facilities be expanded in order to gain experience with limited, but no less valuable, triple interaction experiments-that could then be applied to the design of a national capability.

\section{c. Manpower}

The Workshop noted and expressed concern over a decline and a deficit in the numbers of students being suitably trained in laboratory cloud physics and cloud chemistry. The ability to attract, train, and renew manpower is the life-blood of any discipline. Thus, the workshop recommends

1) that the forgoing statements of accomplishments, relevance and confidence in the future potentials for productive research in laboratory cloud physics and cloud chemistry, and the ongoing specific recommendations, be supported to enable the discipline to attract new manpower;

2) that the necessary manpower (graduate students and postgraduate scientists and engineers) be educated and trained in present facilities, and through collaborative efforts in new, consolidated facilities as they come on line.

\section{Summary}

The discipline of laboratory cloud physics and cloud chemistry, in summation, has been a persistent and significant con- tributor to breakthroughs in describing and quantifying the nature and effects of the evolution of clouds, aerosols, and gaseous constituents in the wet atmosphere, and it has played an essential role in systematically guiding the developments and integrating the results of cloud modeling and field studies.

Laboratory cloud physics and cloud chemistry consequently have contributed very substantially to knowledge required for applied problem-solving in the atmospheric and related sciences: remote sensing, "wet" air quality (from cooling-tower plumes to acid rain and nuclear winter), planned and inadvertent cloud modification, climate, quantitative precipitation forecasting, the microburst phenomenon, aircraft icing, frost protection, and other fields. The high priority laboratory investigations defined in this workshop (Experiments 1-10, Section 7) are fundamental to progress in these areas. Therefore, the common ground that basic cloud physics and cloud chemistry share in all of these fields will continue to give the laboratory work relevance in addressing problems of national economic and societal significance.

In addition to the improvement of ongoing research, a completely new set of experiments is proposed on the interactions of different types of cloud and precipitation particles, as normally occurs in nature. Such conditions require new equipment, within a facility or facilities suitable for a wide variety of experimental work, such that a combining of resources results in collective capabilities that far exceed the sum of the components. An expedient, in-depth examination of the possibilities is needed.

The workshop concludes that the field laboratory cloud physics and cloud chemistry has a standing record of highly significant contributions. The relevance of the discipline is clear and wide-ranging. Enhancements are needed to bring this laboratory research into appropriate balance with field and modeling research. The needs of laboratory cloud physics and cloud chemistry, as defined in the workshop recommendations, can appropriately be fulfilled with the confidence that new financial support for laboratory research will be met with fitting and worthy progress that will be of further significance to the atmospheric and related sciences.

\section{References}

Cotton, W., 1979: Cloud physics: a review for 1975-1978 IUGG quadrennial report. Reviews of Geophysics and Space Physics, 17, 1840-1851.

Hallett, J., 1983: Progress in cloud physics 1979-1982. Reviews of Geophysics and Space Physics, 21, 965-984.

Hobbs, P. V., 1974: Ice Physics, Clarendon Press, Oxford, England, $837 \mathrm{pp}$.

Olsen, W., Ed., 1981: Survey of aircraft icing simulation test facilities in North America. NASA Tech. Memo. 81707, 15 pp. (available from NASA Lewis Research Center, Cleveland, Ohio 44135.)

Pruppacher, H. R., and J. D. Klett, 1978: Microphysics of Clouds and Precipitation, Reidel, Boston, 714 pp. 


\title{
Eighth Conference on Fire and Forest Meteorology 29 April-2 May, 1985, Detroit, Michigan
}

\author{
Linda R. Donoghue ${ }^{1}$
}

\author{
Chairperson
}

\begin{abstract}
This report summarizes more than 40 papers presented at the Eighth Conference on Fire and Forest Meteorology held in Detroit, Michigan, from 29 April-2 May, 1985. The contents of these papers represent recent applied research and scientific advances in areas of firebehavior modeling, weather and fire effects on natural resources, air pollution, fire-danger rating, and fire-weather forecasting.
\end{abstract}

\section{Introduction}

The effects of climate and weather on wildland ecosystems and fire are intrinsically complex, yet some overriding generalizations can be made about their interactions. The seasonal progression of climatic elements controls the establishment and growth of vegetation and, consequently, the amount of fuel. Variations in climate and weather can bring fuel to a dry and flammable state, controlling the probability of ignition and/or sustained combustion. Once fuel is ignited, weather elements affect the behavior of a fire and the difficulty of control (Chandler et al., 1983; Reifsnyder, 1978).

Fire and forest meteorology, which encompasses these complex atmosphere-forest-wildfire interactions, was the subject of a conference held from 29 April to 2 May 1985 in Detroit, Michigan. The conference, jointly sponsored by the Society of American Foresters and the American Meteorological Society, brought together forest managers, scientists, and operational meteorologists from the United States and Canada to exchange information and present recent scientific and operational advancements in fire and forest meteorology.

The formal papers presented at the conference, though of wide technical and geographical scope, were organized into six sessions: 1) Fire-behavior modeling; 2) Weather and fire effects on natural resources; 3) Fire-weather climatology; 4) Air pollution; 5) Fire-danger rating; and 6) Fire-weather forecasting. Each session is summarized below.

\section{Fire-behavior modeling}

C. E. Van Wagner introduced this session with a keynote address on blending the art and the science of fire-behavior modeling. In the past six or seven decades of North American fire research, three basic modeling approaches have been used, singly or in combination, to explain forest-fire behav-

\footnotetext{
${ }^{1}$ U.S. Department of Agriculture-Forest Service, North Central Forest Experiment Station, 1407 South Harrison Road, East Lansing, MI 48823
}

ior: mathematical, laboratory, and empirical. American researchers have developed primarily a blend of laboratory and mathematical models, while the Canadian approach has been empirical, bolstered by mathematical principles and lab work. And yet, Van Wagner noted, both approaches have tended to converge. Both have classified the forest into fuel types or models, each with its specific set of equations for rate of spread, intensity, and so on. He cited two reasons for this: real-time identification of the fuel complex must be quick and simple for the practitioner; and the final result, no matter what the approach, must be a set of equations in terms of weather and topographic variables. Van Wagner closed his discussion with a list of worthwhile unsolved challenges and with some simple words of advice: “. . . in a subject as complex as fire science, [where] pure scientific logic just doesn't seem to be enough, the researcher had better be something of an artist as well as a scientist."

A few of the conferees described fire-behavior models and/or data relevant to modeling efforts. B. D. Lawson, presenting a paper coauthored with B. J. Stocks, M. E. Alexander, and C. E. Van Wagner, discussed the interim edition of the Canadian Forest Fire Behavior Prediction (FBP) System, which provides fire managers with site-specific fire-behavior information for a number of important fuel types. Although the FBP System is designed to produce estimates of rate of spread (ROS), fuel consumption, and frontal fire intensity, only the ROS component has been completed and subjected to user trials. The system provides tables and graphs of ROS and Initial Spread Index (ISI) relationships for 14 major Canadian fuel types, procedures for adjusting FBP Sytem inputs and ROS outputs, and methods for calculating and plotting predicted fire sizes. Even though improvements will be made to the FBP System, this interim edition represents the best available information on fire spread in Canadian forests.

In the next presentation, M. E. Alexander traced the derivation and evaluation of a mathematical model that relates the length-to-breadth (L/B) ratio of a free-burning fire to surface wind speed in a given fuel type. He reported that predicted L/B ratios compared favorably with actual observations of surface and crown fires in a wide variety of coniferous forests and over a wide range of wind speeds. His equation was subsequently used in a simple elliptical firegrowth model in the Canadian FBP System to calculate and plot the area and perimeter of free-burning fires originating from a point ignition in various timber fuel types.

A great deal of fire-effects information is related to soil heating. Consequently, if soil heating can be predicted, some fire effects can be related to quantified fire behavior. D. Pafford and his associates, V. K. Dhir, E. B. Anderson, and J. Cohen, proposed a moving flame-front model to determine 
the soil-surface-temperature distribution. The model relates fire characteristics to soil heating rate and soil temperature by depth. It indicates that the location of maximum surface temperature depends only on flame geometry, but the magnitude of the surface temperature depends on both flame geometry and the physical properties of the flame and the soil. And, Pafford stressed, once the model was corrected to include embers, its predictions of soil-temperature distributions compared quite well with experimental laboratory data.

In a different vein, O. Robinson reported on the Finley Creek firestorm that occurred in Humboldt County, California, in September 1973. After describing the fuels and topography as well as antecedent climate and weather conditions, he traced the behavior of the fire from its ignition to the time it was controlled five days later. Based on this case study, Robinson identified meteorological precursors to firestorms that researchers should consider in their fire-modeling efforts.

The last two presentations in this session focused on applications of fire-behavior models. C. L. Rice, presenting a paper coauthored with R. E. Martin, demonstrated the use of BEHAVE, a fire-behavior prediction and fuel-modeling system, to determine changing potential fire behavior in California north-coast scrub vegetation growing on different aspects and positions on a slope. Rice foresees the use of BEHAVE in urban interface areas to guide homeowners, urban planners, government officials, developers, and insurance companies, all with a stake in the protection of communities adjacent to highly flammable wildlands.

L. A. Salazar determined whether or not fire behavior simulated for one geographical area would also apply to an adjacent area with different meteorological influences. Using four fuel models, she compared simulated rates of spread and fireline intensities of wildfires in the northern Rocky Mountains with those in the Pacific Northwest. She found that, overall, they were quite similar. This indicates that the simulation models used were not very sensitive to differences in locations of weather sources within these two areas.

\section{Weather and fire effects on natural resources}

This session opened with a keynote address by W. T. Sommers, who postulated that significant theoretical advances in meteorology usually result from some impetus provided by new technology. Using a series of examples, he traced the historical development of atmospheric-science theories, showing the critical dependence of those theoretical advances on new technology. He remarked that, "meteorology began as a modern science about 100 years ago when technological advances allowed us to observe, transmit, format, analyze, and distribute information based on measurable atmospheric variables, in a timely manner." Placing the development and current status of fire and forest meteorology within the context of this historic development, Sommers identified several problems acerbating the acquisition of forest-meteorology information. He concluded on a hopeful note that recent and anticipated technological advances will be vehicles for forest and fire meteorology to progress in ways similar to the evolution of general meteorology.

One such technological advance is FWIS (Forestry Weather Interpretation System), an automated, near-real-time forestry weather system, which provides timely weather information to forest managers. J. T. Paul, from a paper written with J. M. Pierovich, summarized some of the administrative and technical problems and opportunities encountered in developing and testing the system. In addition to a number of other topics, he also described the composition of FWIS models, FWIS outputs and products currently on line, and user costs.

Several conferees presented studies relating weather and fire effects to changes in forest vegetation. R. W. Johansen compared eight calculated indices of drought with live-fuel moisture contents to determine if unusually intense summer fires in the Atlantic Coast States are due to low moisture contents in living vegetation during periods of drought. He found that more-intense summer fires during dry periods usually cannot be blamed on lower moisture contents of living fuel. Rather, additional available litter fuel is more likely the reason for higher fire intensities.

D. D. Wade assessed short-term fire effects on the survival and growth of young loblolly pine plantations burned in winter and spring wildfires. He reported that the species was remarkably fire resistant, although it's more susceptible to early-winter and spring fires than to late dormant-season fires. Virtually all trees alive after the first post-fire growing season were well on their way to recovery, suggesting that, in young loblolly pine, most fire mortality occurs soon after the fire and can be predicted at that time using crown scorch, needle consumption, and terminal leader conditions.

On the West Coast, R. E. Martin and his coauthor, J. B. Kauffman, demonstrated that prescribed fire can be used to reduce broadleaved competition prior to harvest in Sierra Nevada mixed-conifer stands. Though burning under different weather and fuel-moisture conditions produced large differences in plant and seed response, prescribed burns consuming the most duff were most effective in killing resprouting shrubs and hardwoods. Timing the burns to coincide with drier fuel conditions and active shrub growth also increased shrub mortality.

A. L. Koonce and L. F. Roth studied the effects of dwarf mistletoe on fuel characteristics of precommercial ponderosapine stands. Koonce reported that infected stands have more fuel in the lower $2 \mathrm{~m}$ of the canopy and a higher ratio of dead to live fuel. Overall, diseased stands have higher fuel loadings than healthy stands and the disease-affected fuel is more flammable and closer to the ground, promoting faster fire spread. Koonce suggested that these fuel characteristics be considered if prescribed burning is planned for such stands.

To better assess the impact of tropical biomass burning on global trace gas budgets, J. Fishman with his coauthors, P. Minnis and M.Z. Taylor, explored the use of satellite data to identify regions where significant forest or savannah fires are occurring and to examine their relationship to anomalies in ozone concentrations. Fishman reported that biomass burning and deforestation practices during the dry season in northern Brazil are a significant source of tropical tropospheric ozone. The size of the fires and the associated dry weather made it possible to identify fires and quantify smoke output using visible and infrared geostationary-satellite data. 


\section{Fire-weather climatology}

W. E. Reifsnyder's keynote address dealt with a much-publicized topic, nuclear winter. He pointed out that predicting the number and distribution of ignitions in nonurban areas resulting from nuclear explosions is a prerequisite to determining the amount and distribution of smoke injected into the atmosphere and, consequently, the effects of nuclear winter. Reifsnyder described a methodology, developed with his coauthor, J. K. Berry, to improve estimates of wildland areas ignited by a particular nuclear scenario. The methodology required detailed analyses of factors influencing ignitions: thermal yield of nuclear weapons, intervisibility of fuel and fireball, atmospheric transmissivity, fuel size, and fuel moisture content. These variables were systematically combined, using a map overlay and analysis system, to determine the pattern of potential forest ignitions for a given area. The pattern was modified by eliminating bodies of water and areas where snow cover or current precipitation preclude sustained ignition. The final product was a map of expected ignition areas resulting from a specified combination of nuclear weapons. Although only ignitions were considered, Reifsnyder concluded that with additional maps of wind speeds and other fire-behavior variables, fire-spread maps could also be prepared. Using historical weather data, it would then be feasible to create a climatology of fire potential to enhance predictions of smoke from burning wildland fuels ignited by nuclear detonations.

In the next presentation, A. J. Simard examined the El Niño/Southern Oscillation phenomena and possible teleconnections to weather in the U.S., noting that El Niño events may affect annual wildfire activity (fire occurrence and area burned). He and his coauthors, D. A. Haines and W. A. Main, found that in 16 States, primarily in the South, fire activity decreases during El Niño years, but there is little or no evidence to support a relationship between El Niño events and wildfire activity in the remaining contiguous states. $\mathrm{He}$ concluded that, in the South, El Niño events can be used to predict above- or below-average annual fire activity prior to the start of a fire season.

The next three speakers looked at issues related to measuring drought and its impact on fire activity. T. R. Karl remarked that NOAA routinely publishes the Palmer Drought Severity Index (PDSI), which is used by land managers to monitor environmental conditions related to forest-fire danger. One problem, however, is that the PDSI is sensitive to its calibration period (the period of record used to establish whether conditions are unusually dry or wet). As an alternative, Karl recommended the Palmer Moisture Anomaly Index ( $\mathrm{Z}$-index), which is less sensitive to changes in the calibration period and is likely to be a better estimator of forestfire danger than the PDSI. The Z-index contains all the physical attributes of the PDSI except that it is more responsive to short-term moisture anomalies.

In a related paper, $T$. $R$. Heddinghaus reported that the PDSI, Crop Moisture Index (CMI), and percentage probability projections of the PDSI for seven dry/wet categories are available from the Climate Analysis Center's (CAC) newly installed request/reply dial-up system for near-realtime use. He also noted that, because of a USDA Forest Service request, the PDSI is now routinely calculated year round.
R. B. Street examined the relationships of synoptic weather descriptors (soil-moisture $\mathrm{Z}$ scores and the $50 \mathrm{kPa}$ height anomaly) and two components (Drought Code and Buildup Index) of the Canadian Forest Fire Weather Index to annual and within-year variations in fire severity in western Canada. He found that correlations appear to exist between severe-fire-danger days and increasing values of the Drought Code and Buildup Index, decreasing values of the soil-moisture $\mathrm{Z}$ scores, and the persistence of a $50 \mathrm{kPa}$ ridge.

M. H. McCutchan concluded this session by presenting results of regression models for extrapolating temperature, mixing ratios, and the $u$ and $v$ components of wind in mountainous terrain. These models were developed from data collected on San Antonio Mountain, an isolated, conically shaped mountain in north-central New Mexico. He noted that such models, which incorporate time and the effects of elevation and aspect, must be developed to extrapolate and interpolate meteorological data to other times and to specific sites in complex terrain.

\section{Air pollution}

In his keynote address, J. E. Pinkerton stated that determining how pollutants are transferred from the atmosphere to forest ecosystems has become a critical research task due to possible links between air quality and forest health. In reviewing the major hypotheses concerning how different pollutants damage forest ecosystems, he conjectured that absorption of gases, impaction and sedimentation of particles, and deposition of ions contained in rain, dew, and fog may all be important factors. Noting that testing these hypotheses requires quantitative knowledge about the transfer of substances from the atmosphere to forest ecosystems, Pinkerton identified areas of current research and those that need to be investigated further. He stressed that, with the urgency of the problem and the increased spending levels to solve it, there is considerable opportunity for forest meteorologists to contribute to a better understanding of the pollution-transfer mechanisms and, ultimately, to resolve whether or not air pollutants represent a significant stress factor for forests.

In a subsequent paper, D. L. Peterson described how treering analysis can be used to assess the impact of air pollution and fire on long-term tree growth. He focused on sampling and analysis procedures that are critical for determining the effects of these nonclimatic factors. He remarked that a consistent trend of high or low ring-width index and high autocorrelation in the chronology may indicate some effects of nonclimatic factors on tree growth.

D. V. Sandberg described a model for predicting total biomass consumption and particulate emission yield from broadcast-burning conifer logging slash in the Pacific Northwest. Requiring only three inputs (large woody fuel loading, large-fuel moisture, and duff-moisture regime), the model predicted a three percent decrease in air-pollutant emissions for each one percent increase in large-fuel moisture. In addition, it predicted a 25 percent reduction in emissions by burning during a wet duff-moisture regime. 
On a similar note, R. D. Ottmar reported on a study in which he and his coauthors, S. N. Little and J. Ohmann, developed two duff-reduction equations, based on data from numerous broadcast burns, that will help managers set utilization standards and schedule burns to mitigate impacts on air resources. The first equation used large-fuel consumption to estimate duff reduction when duff is wet, and the second used the diameter reduction of large woody fuels when the duff is dry.

Because demands for firewood are increasing, pesticidetreated trees are an obvious source of supply. But, little is known about what happens to pesticides when treated wood is burned in the open or in a home. From a paper written with H. B. Clements, P. B. Bush, D. G. Neary, and J. W. Taylor, C. K. McMahon presented the results of a study in which wood treated with five herbicides and two insecticides was burned under controlled conditions to simulate a wide range of thermal environments found in domestic wood stoves and fireplaces. McMahon demonstrated that, under conditions of rapid (flaming) combustion, most organic pesticides decompose readily. He also noted that under slow burning (smoldering) conditions, the amounts released were dependent on the properties of the pesticides. Because of the uncertainty of ventilation and temperature in many domestic wood-burning devices, however, he advised a cautious approach to burning wood treated with organic pesticides pending further research.

The last speaker of this session, M. A. Fosberg, presented two papers. The first described the use of two simulation models to study smoke-dispersal processes in complex terrain: a three-dimensional wind model to identify wind patterns in drainage flows and a three-dimensional dispersion model to predict trajectories and diffusion. Both compared well with more-complicated models and with wind and tracergas data. The results from the dispersion model in particular suggested that the trajectory calculation is the most significant factor in plume modeling in complex terrain. These results were supported by a smoke-plume simulation which paralleled outcomes of similar modeling efforts.

In his second paper, Fosberg presented results from an exploratory study that was designed to provide meteorological information related to the transport of air pollutants from the southern end of the San Joaquin Valley in California into the mountain areas of the southern Sierra Nevada. He found that the lower gorge of the Kern River showed mass flux an order of magnitude below that observed in the mid-and uppercanyon areas and that deep mixing occurred in the San Joaquin Valley. These results suggested that little exchange of mass took place between the San Joaquin Valley and the Kern River Canyon through the gorge. Rather, transport of mass from the valley probably took place at ridgetop level and was subsequently entrained into the local circulation that developed above the gorge.

\section{Fire-danger rating}

In the opening paper of this session J. D. Cohen stated that, while certain technical aspects of the National Fire-Danger Rating System (NFDRS) may be improved, dissatisfaction with the System may be largely a result of managers' unreal- istic expectations of what it can provide-temporal and areal information comparable to that of the Fire Behavior Prediction System (FBPS). To explore this issue further, Cohen traced the development of the NFDRS and the FBPS, compared their equations, and examined the functional form of their models. Though both systems assess similar fire-behavior characteristics, he concluded that the NFDRS assesses broad-areal fire situations, whereas the FBPS is site-specific. The primary difference between the NFDRS and the FBPS is the resolution of the input data, and consequently, the resolution of the results. Thus, Cohen argued, managers need to be aware of these differences when analyzing their needs for information. Improving technical aspects of the NFDRS will not change the inherent resolution of the System's output.

The operational validity of the NFDRS in the Northeast was considered by W. A. Main, who presented a study in which he and his coauthors, D. A. Haines and A. J. Simard, related predictions from each of the 20 NFDRS fuel models to observed rates of spread and flame lengths on wildfires. Using six different tests to evaluate each model, they found that fuel models $\mathrm{K}$ and $\mathrm{E}$ best fit field observations of fire behavior in the Northeast. Main cautioned, however, that no single model is best for all purposes. Managers must decide which fuels or test criteria are most important and choose a fuel model on that basis.

On a philosophical note, C. E. Van Wagner considered several principles related to the construction and presentation of long-term moisture indexes in forest-fire-danger rating. He compared five indexes that are or have been used to represent long-term weather, noting especially the timelag feature of each index. He constructed a generic drought index to show the importance of timelag as the principal comparable parameter and addressed questions concerning the absolute versus relative drought-index presentation, the negative exponential drying principle, and the significance of drought indexes. Van Wagner concluded, however, that the role of long-term indexes in fire-danger rating is distinctly subsidiary to that of the principal short-term indicators of fire-ignition potential and rate of spread.

Following Van Wagner, several conferees presented papers on fuel mositure. In her first paper, coauthored with R. E. Martin, C. L. Rice described differences in patterns of moisture trends and levels of moisture content for two vegetative types (oak-bay woodland and north-coastal scrub) in California during the 1984 fire season. Rice concluded that data from a statewide fuel-moisture-content monitoring program in chaparral cannot be applied universally to these other species because of species differences in seasonal moisture trends and levels. She also discussed differences in moisture contents of new and old growth as well as the effects of slope and aspect on live-fuel moisture.

In a companion paper also coauthored with R. E. Martin, C. L. Rice described the effects of precipitation on live-fuel moisture contents of five oak-bay woodland and north-coastal scrub species. After $\frac{1}{2}$-inch or more of precipitation, there was a delay in the increase of fuel moisture. The timelag and magnitude of the increase varied with the type of growth (new or old), species, and season. Understanding these differences in response to precipitation can be useful in timing prescribed burns and planning when and how much to water shrublands in the urban interface to enhance fire protection. 
J. W. van Wagtendonk described a study in which the moisture contents of woody fuels of various size classes were correlated with the moisture contents of litter layers at different depths. He and his associate, W. M. Sydoriak, found good correlations between the moisture contents of the two smallest diameter classes and the two shallowest depth classes. They also found that woody and duff moisture contents correlated better for short-needled conifers than for long-needled conifers. Van Wagtendonk concluded that the definitions for fuel-moisture timelag classes are adequate for one-hour and 10-hour duff and woody fuels. In addition, estimates for one-hour and 10-hour duff moisture contents can be made from corresponding woody moisture contents.

Next, H. E. Anderson pointed out that fine fuels (one-hour timelag) do not all have the same moisture response and, based on data from a wide range of fine fuels, changes in moisture content generally do not follow a negative exponential function overtime. Adsorption response times were generally longer than desorption response times; weathering for one-year shortened response times but they still remained longer than one hour; and response times became longer the closer conditions were to the final state. Thus, Anderson contended, managers should be aware of problems that exist in moisture response times of fine forest fuels. Adjustments must also be made in fuel-moisture models to reflect actual response times in order to improve predictive capabilities.

The last two papers in this session described methods to predict people-caused wildfire occurrence in Canada. T. $\mathbf{J}$. Lynham and D. L. Martell analyzed "historical peoplecaused forest fire occurrence in order to develop a mathematical model that explains why annual fire occurrence varies from year to year and place to place in the province of Ontario." Lynham presented a regression model that predicts annual resident fire occurrence as a function of population, year, and the Fine Fuel Moisture Code (FFMC) of the Canadian Forest Fire Danger Rating System (CFFDRS). Individually, the FFMC explained 47 percent of the variation in annual resident fires, and the entire model accounted for 60 percent of the variation in these fires.

D. L. Martell then described logistic regression techniques used to develop models that yield probabilistic predictions of daily people-caused forest-fire occurrence in Ontario. $\mathrm{He}$ and his coauthors, S. Otukol and B. J. Stocks, used daily observations in fire-danger-rating indices from the CFFDRS to predict daily people-caused fire occurrence by wildfire cause. Based on preliminary field tests, they found that their models performed best for the early-summer fire season and that recreation-related-fire-occurrence predictions were less accurate than those produced for other fire causes.

\section{Fire-weather forecasting}

In the keynote paper for the last session of the conference, $F$. M. Fujioka stressed the importance of fire-weather network design and its impact on a fire manager's ability to make weather-related decisions. After summarizing previous methods that had been developed to objectively design fire-weather networks, he outlined a new method that determines the optimum number and location of stations for specific meteoro- logical conditions identified by a manager. Fujioka illustrated the method, showing how it selects station locations along a transect and determines the number of stations, and projected how it will be used to improve the diagnosis of Santa Ana occurrences in southern California.

In a paper coauthored with B. G. Brown and D. L. Radloff, A. H. Murphy described procedures and practices used to formulate and evaluate spot fire-weather forecasts (SFWFs) for prescribed fires. He summarized results concerning forecast lead times, elements in forecasts and their perceived importance to the forecaster, and forecast formats and modes of presentation. He also identified important information sources used to formulate SFWFs and the manner in which forecasters express uncertainty in their SFWFs.

"Prescribed burning and wildfire control," the next speaker, G. L. Achtemeier, emphasized, "are crucially dependent upon the current and predicted state of the local wind and stability." To enhance a manager's ability to predict windshifts, Achtemeier designed a numerical prediction model to produce short-range forecasts, based on readily available in situ and remotely sensed observations, of mesoscale wind fields near the ground. He presented results of a "pilot study" simulation of the wind field and temperature over Georgia and northern Florida during a 22-hour period in June 1977 in which a major wildfire occurred. Given the encouraging results, Achtemeier concluded, the model, after some modification, will be useful for operational predictions of local winds.

B. Janz demonstrated that ongoing plots of 500-mb height anomalies (i.e., departures from normal) can help fire managers evaluate fire-danger trends and potential fire behavior. $\mathrm{He}$ and his associate, N. Nimchuk, showed that the charts can provide a visual fire-weather history of a fire-management unit and effectively "flag" impending critical fire situations. Because the charts are simple to construct and maintain, they lend themselves to effective operational use.

The next presenter, F. M. Fujioka, noted that previous probability analyses of fire-weather indices yielded coarsely modeled distributions or a refined multinomial with many parameters. Fujioka and his coauthor, T. Tsou, believe a more-parsimonious but representative description of the data is possible using standard probability models of continuous random variables. To demonstrate this, they used data from four fire-weather stations in southern California to compute the Fosberg Fire Weather Index. After comparing the empirical distribution of the index at each test site with normal, lognormal, Gumbel, and Weibull distributions, they found that the Gumbel distribution clearly provided the best fit. Fujioka noted the ways in which such a continuous probability model can aid fire-management decision making.

Results of a national survey designed to evaluate the National Weather Service's (NWS) Fire Weather Program were reported by W. T. Parker. The survey showed that land managers are generally satisfied with the current program and related services. The increasing importance of prescribed burning and smoke management nationwide, however, indicates that a changed emphasis in program activities may be necessary in the near future.

A. H. Murphy and his associates, B. G. Brown and D. L. Radloff, designed a study to evaluate the ability of NWS fire- 
weather forecasters to prepare SFWFs for prescribed burns in probabilistic terms. Experimental probability forecasts of temperature, wind direction, wind speed, and relative humidity were compared with observations of these elements taken at prescribed burn sites at approximately the planned ignition time reported to the forecasters. Murphy reported that the temperature and wind-direction forecasts were quite reliable. The probabilistic forecasts of wind speed and relative humidity, however, were considerably less successful, exhibiting substantial overforecasting.

The last paper of this conference was offered by J. M. Saveland, who described a technique for forecasting fire danger and lightning-fire occurrence for wilderness areas in Idaho. He found that, given conditions in mid July and assuming persistence, fire personnel can forecast the rest of the fire season fairly accurately as well as the probability of different outcomes. For example, the technique accurately predicted the onset of high fire danger nine times out of 10 and lightning-fire occurrence eight times out of 10 . Saveland concluded that, when augmented by other weather information, this procedure could help fire managers decide whether or not to allow lightning fires to burn in wilderness areas. It could also help them to develop fire-management prescriptions and to schedule summer prescribed burning operations.

The papers presented at the conference dramatically illustrate the state of the art in the field of fire and forest meteorology. Forest managers, scientists, and operational meteorologists not only presented and discussed their operational problems, research results, and new technology but also identified where they should collectively direct future efforts. A broad range of technical material was presented that was of both national and international interest. These aspects of the conference bode well for the future of fire and forest meteorology.

\section{References}

Chandler, C., P. Cheney, P. Thomas, L. Trabaud, and D. Williams, 1983: Fire in Forestry Volume I: Forest Fire Behavior and Effects. John Wiley \& Sons, Inc., New York, N.Y. 298 pp.

Reifsnyder, W. E., 1978: Systems for evaluating and predicting the effects of weather and climate on wildland fires. World Meteorological Organization, Special Environmental Report No. 11, WMO-No. 496.40 pp. announcements (continued from page 1361)

\section{meetings of interest}

31 January 1987. The Oregon Branch-American Meteorological Society Third Conference on Weather, Climate, and Hydrology of the Pacific Northwest will be held on Saturday, 31 January 1987 in Portland, Oregon. The conference will be held at the Corps of Engineers briefing room at the Custom House, 220 N.W. 8th in Portland. Papers are solicited on all aspects of meteorology as they apply to the Pacific Northwest.

This meeting will be a "mini" technical conference with a format similar to, but less formal than, AMS national conferences. For this conference, the term "paper" is used somewhat loosely, since the main purpose of the meeting is simply to share information. Formal papers are fine, but information about ongoing projects, forecast techniques, new equipment etc. is also welcome. In that case, a "paper" may consist of just an outline or speaking notes.

Abstracts of 100-300 words describing the presentation are required and should be sent to one of the program co-chairmen, George Miller, c/o National Weather Service, 5420 N.E. Marine Drive, Portland, OR 97218-1089, or Don Caniparoli, CH2M Hill, 2020 S.W. 4th Avenue, Portland, OR 97201. For more information, contact Don Caniparoli at (503) 224-9190 or George Miller at (503) 221-2340.

22-25 June 1987. A conference on remote sensing, the Eleventh Canadian Symposium on Remote Sensing, will be held at the University of Waterloo in June 1987. The theme of the conference is "Education for the Future." Topics to be covered include not only the educational aspects of remote sensing, but also technical advances and practical uses. Subjects to be discussed include sensors, data acquisition, methodology, processing and analysis, and environmental monitoring. Sponsors of the symposium will include the Canadian Remote Sensing Society of the Canadian Aeronautics and Space Institute, the Canada Centre for Remote Sensing, the Ontario Centre for Remote Sensing, and the Ontario Association of Remote Sensing. Those wishing to submit research papers must do so prior to 11 January 1987. For more information, contact Ms. Pam Loucks, c/o Professor Ellsworth LeDrew, Geography De- partment, University of Waterloo, Waterloo, Ontario, Canada N2L 3G1.

13 July-18 September 1987. The Climatic Research Unit at the University of East Anglia is offering a short course, titled "Understanding Climate," from 13 July to 18 September 1987. The course is designed to broaden the knowledge of climatologists, to educate specialists in other disciplines, and to train data specialists in the efficient use of climate statistics. The course will be held in Norwich, UK. The closing date for applications is 31 December 1986. For further details, please contact The Director, Climatic Research Unit, University of East Anglia, Norwich NR4 7TJ.

\section{Deadlines calendar}

Fellowships, grants, etc.

15 June 1987 Macelwane Annual Award (this issue, p. 1404)

15 June 1987 Hanks and Orville Scholarships (this issue, p. 1404)

Other

31 December 1986 research papers for The Climate Research Unit at the University of East Anglia, course in "Understanding Climate" (this issue, p. 1403)

11 January 1987 research papers for Eleventh Canadian Symposium on Remote Sensing (this issue, p. 1403)

15 January 1987 applications for National Research Council senior and postdoctoral research associateships (this issue, p. 1403)

13 February 1987 requests for NCAR aircraft (September BULLETIN, p. 1131)

1 March 1987 requests for NCAR field-observing support (September Bulletin, p. 1131) 